\title{
The Kinetics of the Oxidation of Lysine by $\mu$-Peroxo-Bridged Binuclear Cobalt (III) Complex of Succinimide in Aqueous Hydrochloric Acid Medium
}

\author{
Ahmed Adetoro $^{* 1}$, Suleiman O. Idris ${ }^{2}$, Ameh D. Onu ${ }^{3}$ and Friday G. Okibe ${ }^{2}$ \\ ${ }^{l}$ Department of Chemical Science, Yaba College of Technology, Yaba, Lagos \\ ${ }^{2}$ Department of Chemistry, Ahmadu Bello University, Zaria \\ ${ }^{3}$ Department of Chemistry, Federal College of Education, Zaria
}

Received $22^{\text {nd }}$ February 2017, Accepted $17^{\text {th }}$ July 2017

DOI: 10.2478/ast-2018-0006

*Corresponding author

A. Adetoro email: lamedaplc@yahoo.com

Tel: +2348036839673

\begin{abstract}
Kinetics of oxidation of Lysine (Lys) and mechanisms by $\mu$-peroxo bis $\left[\right.$ bis(ethylenediamine)succinimidato-dicobalt(III)]dinitratedihydrate; $\left[\mathrm{LCo}\left(\mu-\mathrm{O}_{2}\right) \mathrm{CoL}\right]\left(\mathrm{NO}_{3}\right)_{2} \cdot 2 \mathrm{H}_{2} \mathrm{O}(\mathrm{L}$ $\left.=\operatorname{suc}(\mathrm{en})_{2}\right)$, hereafter the complex, was investigated at $420 \mathrm{~nm}$ wavelength of maximum absorption of the complex under the conditions hydrogen ions concentration $=1.8 \times 10^{-2} \mathrm{~mol} \mathrm{dm}^{-3}$, temperature $=24 \pm$ $1{ }^{\circ} \mathrm{C},\left[\mathrm{LCo}\left(\mu-\mathrm{O}_{2}\right) \mathrm{CoL}^{2+}\right]=1.4 \times 10^{-4} \mathrm{~mol} \mathrm{dm}^{-3}$ and ionic strength $=0.5 \mathrm{~mol} \mathrm{dm}{ }^{-3}$. First order in $[\mathrm{LCo}(\mu-$ $\left.\left.\mathrm{O}_{2}\right) \mathrm{CoL}^{2+}\right]$ and [Lys] were obtained but inverse first order in $\left[\mathrm{H}^{+}\right]$. The proposed overall rate equation is as shown:

$$
\text { Rate }=\left(\frac{k_{1}}{k_{2}}+\frac{K_{1} k_{3}}{k_{4}} \frac{1}{\left[H^{+}\right]}\right)\left[L C o\left(\mu O_{2}\right) \operatorname{CoL}^{2+}\right][L y s]
$$

Rate of the reaction decreases when hydrogen ions concentration increase and exhibited converse effect with increase in concentration of ionic strength from $0.1-1.3 \mathrm{~mol} \mathrm{dm}{ }^{-3}$. Added cations and anions affected the reaction rate and the Michaelis-Menten plot passed through the origin indicating no absence of intermediate complex in the electron transfer processes. Putting all the results obtained together, the most probable reaction mechanism is in favour of outer-sphere and an appropriate rate law is established using steady state approximation.
\end{abstract}

Keywords: Amino acid; Redox reaction; Mechanism; Peroxo-bridge Complex of Succinimide 
concentration of hydrogen ions $=1.0 \times 10^{-3} \mathrm{~mol} \mathrm{dm}^{-3}$, and ionic strength $=0.5 \mathrm{~mol} \mathrm{dm}^{-3}$

\subsection{Kinetic Measurement}

Pseudo-first order conditions with the lysine concentration in at least 10 fold excess over the concentration of the complex were

\subsection{Introduction}

Lysine, an essential amino acids which are the building blocks of protein, are useful in biological research, metabolism, nutrition (fortification of food) and drug industry. These have been oxidized by some oxidizing agents and products such as aldehyde, ammonia, and carbon(IV) oxide have been identified by those workers (Gouda et al., 1986; Goel et al., 2002; Goel and Shama, 2012).

Also the redox reaction of lysine with diperiodatoargentate(III) (Hosamani and Nandibewoor, (2009), hexacyanoferrate ions and potassium permanganate in alkaline medium have been reported Mohanty et al., (2013). The importance of oxidation of $\alpha$ - amino acids from chemical point of view is on its mechanism of metabolism (Devra, 2005). Consequently, it is imperative to explore more redox reactions of this importance compound with a wide of range of substrates.

Presently, there is no reported work on the oxidation of lysine by this complex of interest. This study has therefore been undertaken with a view of gaining further understanding of the redox chemistry of these substrates in hydrochloric acidic.

\subsection{Materials and Methods}

Analar grade of chemicals and reagents were used in this work without further purification. All solutions were prepared with distilled water. The preparation of the complex was according to the literature by measuring $2.91 \mathrm{~g} \mathrm{Co}\left(\mathrm{NO}_{3}\right)_{2} \cdot 6 \mathrm{H}_{2} \mathrm{O}$ (Sigmal Aldrich) into $20 \mathrm{~cm}^{3}$ water, added to this is $1.0 \mathrm{~g}$ succinimide and heated to $70{ }^{\circ} \mathrm{C}$ using heater magnetic stirrer. $1 \% \mathrm{NaHCO}_{3}$ solution was used to maintained the $\mathrm{pH}$ of 6.0 in this reaction. An excess of ethylenediamine was added and stirred at $70{ }^{\circ} \mathrm{C}$ for 30 min. Change of colour from red violet to brown was observed. The mixtures was allowed to cooled to room temperature and after several days, dark brown crystals were filtered, washed with water and cold ethanol and was characterized using UV-Visible and Fourier Transformed Infrared (FTIR) spectrophotometers (Murat and Orhan, 2009). Standard solution of hydrochloric acid was standardized titrimetrically using $\mathrm{Na}_{2} \mathrm{CO}_{3}$ and methyl orange as indicator. Ionic strength was maintained constant using sodium chloride for each run.

\subsection{Stoichiometry}

Spectrophotometric titration using mole ratio concept was used to determined stoichiometry of the reaction. The complex $\left[\mathrm{LCo}\left(\mathrm{O}_{2}\right) \mathrm{CoL}\right]^{2+}$ was maintained constant at $1.4 \times 10^{-3} \mathrm{~mol} \mathrm{dm}^{-3}$ and lysine was varied below and above that of the complex at the used to carried out kinetic runs. Absorbance was recorded on digital photoelectric colorimeter SM202 and the reactions rate was observed by monitoring the rate of decrease in absorbance of the complex at $\lambda_{\max }$ of $420 \mathrm{~nm}$ characteristic of the complex at constant $\left[\mathrm{H}^{+}\right]$, Ionic strength and temperature. Pseudo-first order rate constants $\left(\mathrm{k}_{1}\right)$ for the reaction were obtained from the slopes of the plots of logarithm of absorbance difference against time. Order of the reaction with respect to [complex] was deduced from these plots. The slope of the plots of $\log k_{1}$ versus $\log$ [Lys] indicate the order with respect to [Lys] (Fig. 1). The second order rate constants $\left(\mathrm{k}_{2}\right)$ were obtained from $\mathrm{k}_{1} /$ [complex].

\subsection{Hydrogen Ion Concentration on Reaction Rate}

The changes in the varying concentration of hydrogen ion on the reaction rate was investigated by observing a constant concentration of the complex and lysine while varying the hydrogen ion concentration between $(0.60-1.60) \times 10^{-2} \mathrm{~mol} \mathrm{dm}^{-3}$ (below this range, the reaction was too slow and the converse became the case above this range). Ionic strength, I, was maintained at $0.50 \mathrm{~mol} \mathrm{dm}^{-3}(\mathrm{NaCl})$. The order of reaction with respect to acid concentration was obtained as the slope of the plots of $\log \mathrm{k}_{1}$ against $\log \left[\mathrm{H}^{+}\right]$. The plot of the acid dependent rate constants versus the inverse of acid concentration is given as Figure 2.

\subsection{Changes in Ionic Strength of Reaction Medium}

Sodium chloride was used between the range $(1.0-1.30) \times 10^{-1}$ mol dm${ }^{-3}$ to varies the ionic strength of the reaction medium while maintaining the concentration of the hydrogen ion, complex, lysine (Lys) and temperature $\left(24 \pm 1{ }^{\circ} \mathrm{C}\right)$ constant. The relationship of the reaction rate with changes in ionic strength was determined by plotting $\log \mathrm{k}_{2}$ versus $\sqrt{\mathrm{I}}$ (Fig. 3 ).

The results obtained for the order of reaction, hydrogen ion and ionic strength dependence are shown in Table 1.

\subsection{Added Ions on Reaction Rate}

The effects of cations $\left(\mathrm{Mg}^{2+}\right.$ and $\mathrm{Ca}^{2+}$ ) and anions $\left(\mathrm{HCOO}^{-}\right.$and $\mathrm{CH}_{3} \mathrm{COO}^{-}$) on the reaction rate were observed by the addition of $(40.00-140.00) \times 10^{-3} \mathrm{~mol} \mathrm{dm}^{-3}$ of the ions while keeping all other reaction conditions constant and the outcome shown in Table 2. 


\subsection{Test for Free Radical and Intermediate Complex Formation}

The detection of free radicals in the reaction mixture was by acrylamide polymerization study while presence of intermediate complex was by comparing the electronic spectrum of the partially initiated reaction mixture taken within $400-700 \mathrm{~nm}$ with that of the complex and the Michaelis - Menten plot of $1 / \mathrm{k}_{1}$ versus 1/[lys] (Fig. 4).

\subsection{Results and Discussions}

The stoichiometry gave one mole of lysine consumed by one mole of the complex. This is similar to the stoichiometry in the reaction of lysine with diperiodatoargentate(III) Hosamani and Nandibewoor (2009). Other researchers however reported a mole ratio 1:2 lysine: permanganate (Harihar et al., 2000), Lysine: hexacyanoferrate(III) (Goel and Shama, 2010), lysine:permanganate (Mohanty et al., 2013).

With the concentration of the lysine (Lys) in at least 10-fold excess over that of the complex, pseudo-first order plots of $\log \left(A_{t}\right.$ - $A_{\infty}$ ) versus time were linear to $90 \%$ of the reaction, indicating first order dependence with respect to the complex. The least square plots of $\log \mathrm{k}_{1}$ versus $\log$ [Lys] (Fig.1) were linear with a slope of 0.99 and correlation $r=1.00$ indicating first order dependence in the [Lys]. Therefore the reaction is second order overall. Similar orders were reported by other workers in the oxidation of lysine by different substrates (Hosamani and Nandibewoor, 2009; Goel and Shama, 2010; Mohanty et al., 2013).

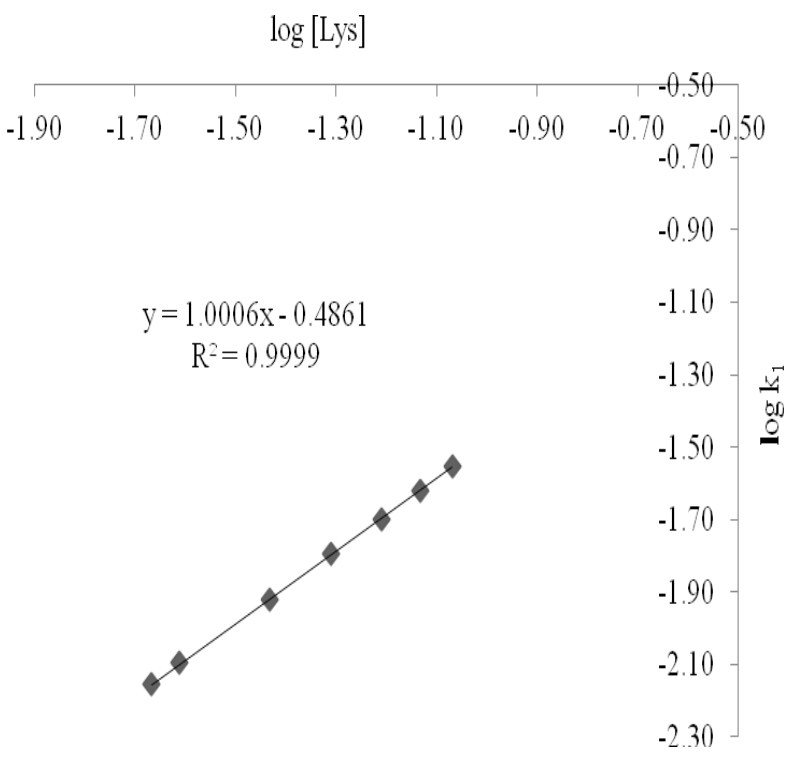

Fig. 1: The plot of $\log \mathrm{k}_{1}$ versus $\log$ [Lys]

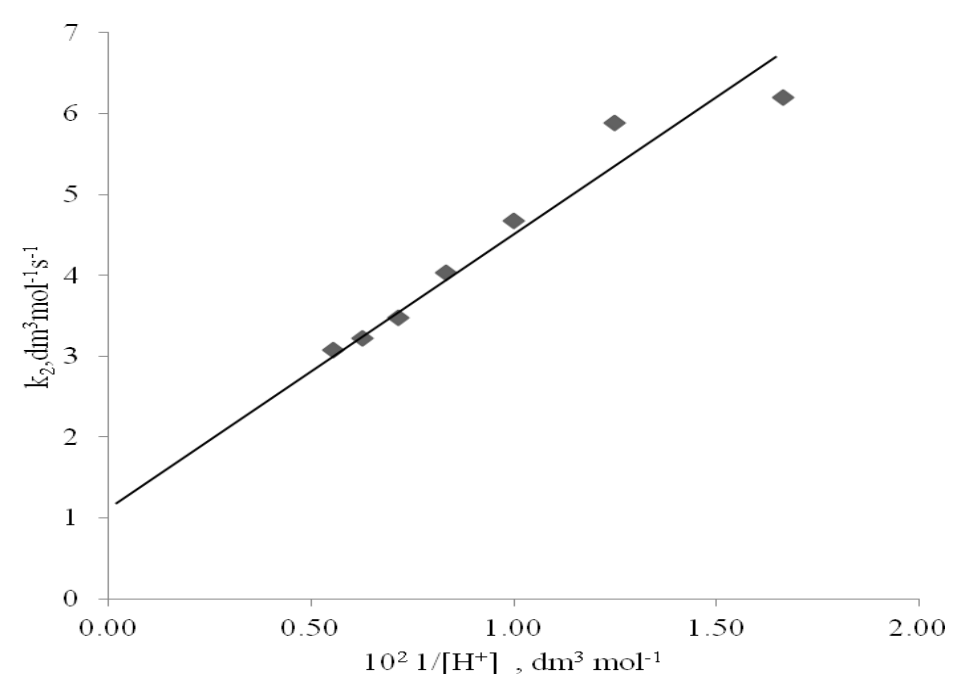

Fig. 2: The plot of $\mathrm{k}_{2}$ versus $\left[\mathrm{H}^{+}\right]^{-1}$

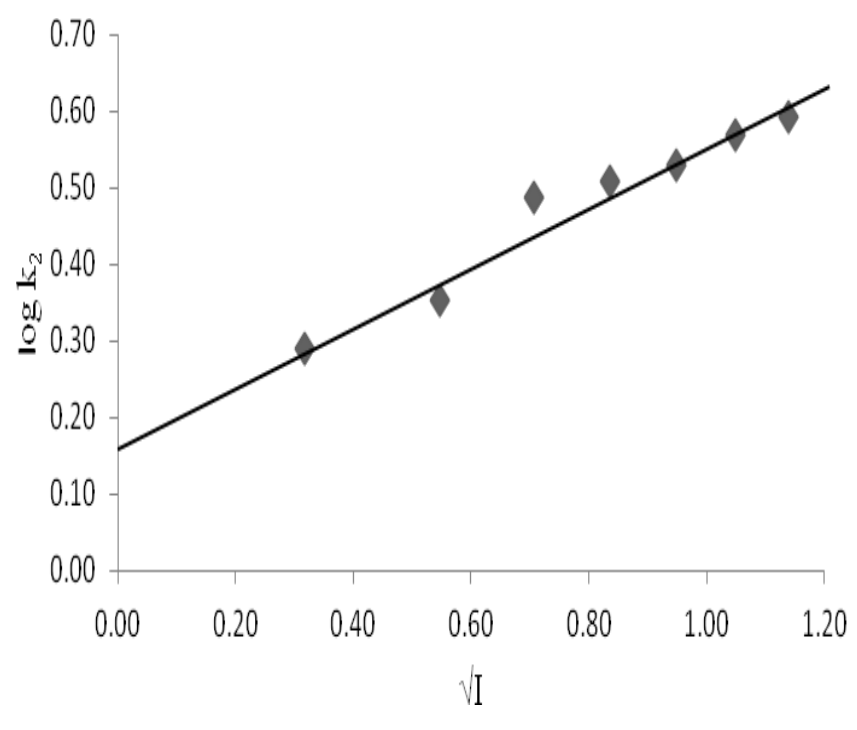

Fig. 3: The plot of $\log k_{2}$ versus $\sqrt{ } \mathrm{I}$

The influence of acidity investigated by changing the concentration of hydrogen ions as shown in Table 1, with all other conditions kept constant. The result obtained as evidenced by the acid dependence rate constants show that the reaction varied inversely with increase in the $\left[\mathrm{H}^{+}\right]$. The least square plots of $\mathrm{k}_{2}$ versus $\left[\mathrm{H}^{+}\right]^{-1}$ (Fig. 2) were straight line with positive intercept. 


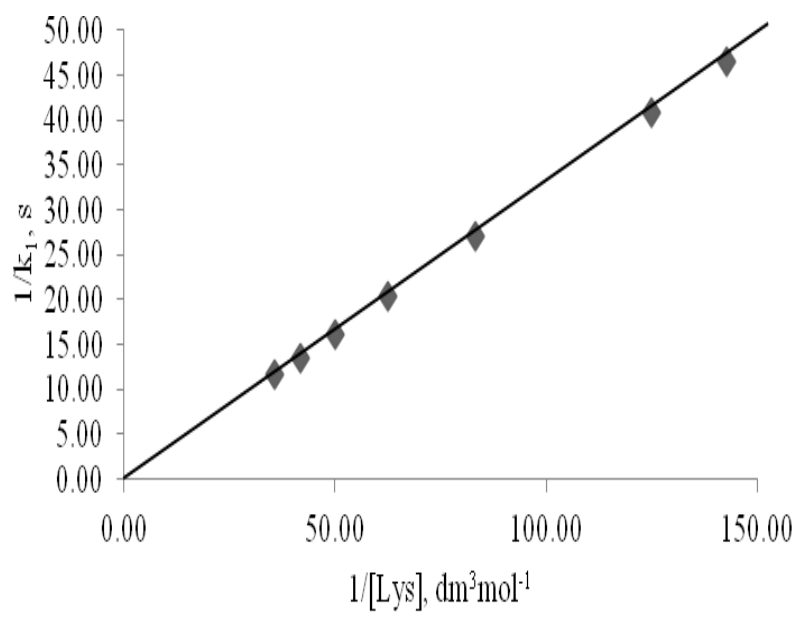

Fig. 4: The plot of $1 / \mathrm{k}_{1}$ versus $1 /[$ Lys]

Acid dependence of this nature has been ascribed to a proton's being a product of a pre-equilibrium step and the reaction involves two parallel pathways in which both the unprotonated and the deprotonated reactant species are involved in the rate -

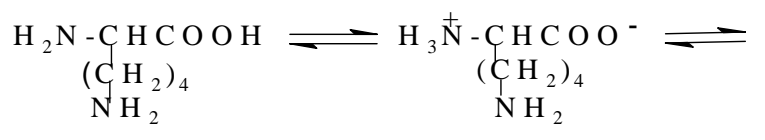

$$
\log \mathrm{k}=\log \mathrm{k}_{\mathrm{o}}+1.02 \mathrm{Z}_{\mathrm{a}} \mathrm{Z}_{\mathrm{b}} \sqrt{\mathrm{I}}
$$

Table 1: Pseudo-first order and second order rate constant for the redox reaction of lysine by $\left[\mathrm{LCo}\left(\mu-\mathrm{O}_{2}\right) \mathrm{CoL}\right]^{2+}$ in aqueous $\mathrm{HCl}$ medium, $\lambda_{\max }=$ $420 \mathrm{~nm}, \mathrm{~T}=24 \pm 1{ }^{\circ} \mathrm{C}, \mathrm{I}=0.50 \mathrm{~mol} \mathrm{dm}{ }^{-3}(\mathrm{NaCl}),\left[\left[\mathrm{LCo}\left(\mu-\mathrm{O}_{2}\right) \mathrm{CoL}\right]\right]^{2+}=$ $1.4 \times 10^{-4} \mathrm{~mol} \mathrm{dm}^{-3}$

\begin{tabular}{ccccc}
\hline $\begin{array}{c}10^{2}[\text { lysine }] \\
\left(\mathrm{mol} \mathrm{dm}^{-3}\right)\end{array}$ & $\begin{array}{c}10^{2}\left[\mathrm{H}^{+}\right] \\
\left(\mathrm{mol} \mathrm{dm}^{-3}\right)\end{array}$ & $\begin{array}{c}10[\mathrm{I}] \\
\left(\mathrm{mol} \mathrm{dm}^{-3}\right)\end{array}$ & $\begin{array}{c}10^{3} \mathrm{k}_{1} \\
\left(\mathrm{~s}^{-1}\right)\end{array}$ & $\begin{array}{c}\mathrm{k}_{2} \\
\left(\mathrm{dm}^{3} \mathrm{~mol}^{-1} \mathrm{~s}^{-1}\right)\end{array}$ \\
\hline 0.7 & 1.8 & 5.0 & 21.49 & 3.07 \\
0.8 & 1.8 & 5.0 & 24.48 & 3.06 \\
1.2 & 1.8 & 5.0 & 36.96 & 3.08 \\
1.6 & 1.8 & 5.0 & 48.96 & 3.06 \\
2.0 & 1.8 & 5.0 & 61.80 & 3.09 \\
2.4 & 1.8 & 5.0 & 73.68 & 3.07 \\
2.8 & 1.8 & 5.0 & 85.40 & 3.05 \\
1.2 & 0.6 & 5.0 & 74.40 & 6.20 \\
1.2 & 0.8 & 5.0 & 70.68 & 5.89 \\
1.2 & 1.0 & 5.0 & 56.04 & 4.67 \\
1.2 & 1.2 & 5.0 & 48.36 & 4.03 \\
1.2 & 1.4 & 5.0 & 41.76 & 3.48 \\
1.2 & 1.6 & 5.0 & 38.64 & 3.22 \\
1.2 & 1.8 & 5.0 & 36.96 & 3.08 \\
1.2 & 1.8 & 1.0 & 23.40 & 1.95 \\
1.2 & 1.8 & 3.0 & 27.12 & 2.26 \\
1.2 & 1.8 & 5.0 & 36.96 & 3.08 \\
1.2 & 1.8 & 7.0 & 38.76 & 3.23 \\
1.2 & 1.8 & 9.0 & 40.56 & 3.38 \\
1.2 & 1.8 & 1.1 & 44.52 & 3.71 \\
1.2 & 1.8 & 1.3 & 47.04 & 3.92 \\
\hline
\end{tabular}

determining reaction (Gupta and Gupta, 1984; Wilkins, 2002). At low $\mathrm{pH}$ which is the condition for this reaction, lysine is expected to exist predominantly in the cationic conjugate acid form

(Robert and Cacerio, 1977) as shown in the equation 1.

The product proton in a pre-equilibrium step displayed by the acid dependent study could have possibly occurred through this process.

As regards to the influence of changes in ionic strength of reaction medium, the rate of reaction was found to vary directly with increase in ionic strength of the reaction medium (Table 1).

Results of this nature which is positive Brownsted-Debye salt effect implies an activated complex composed of like charges. The plot of $\log \mathrm{k}_{2}$ against $\sqrt{\mathrm{I}}$ using equation 2 unexpectedly gave a non-integral slope of value 0.34 . The result from the effect of changes in dielectric constant, $\mathrm{D}$, of the medium on the reaction rate using acetone/water mixture (Table 3) reinforced the result from ionic strength dependence study.

The dependence of reaction rate on added ions concentration (Table 2) indicates an enhancement of rate by anions while cations exerted converse effect. Enhancement of rate or otherwise by added ions have been utilized to infer an activated complex in which the nuclear of the reactant partners are not linked by a bridging group - a feature typical of reactions proceeding via the outer sphere mechanistic pathway (Wilkins, 2002).

Acrylamide, a radical scavenger was added to the partially reacted mixture in the presence of excess methanol, there was no formation of gelatinous precipitate. This evidence rules out the likelihood of free radical presence in the reaction. However, free radicals have been implicated in reactions of lysine by other researchers (Harihar et al., 2000; Mohanty et al., 2013).

Michaelis-Menten plot i.e. $1 / \mathrm{k}_{1}$ versus $1 /$ [Lys] (Fig. 4) gave no intercept and also the spectra of the reaction mixture showed no shift in $\lambda_{\max }$. Both evidences show absence of intermediate complex formation in the course of the reaction and these are in favour of reaction occurring via the outer-sphere mechanism. Base on all these results, outer-sphere mechanism is proposed in this reaction and steady state approximation is used in the plausible mechanistic scheme as shown below to explain the experimental data. 
Using steady state approximation, mechanistic scheme

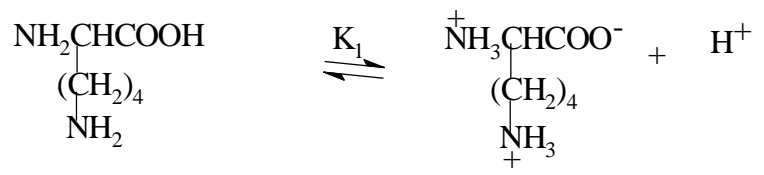

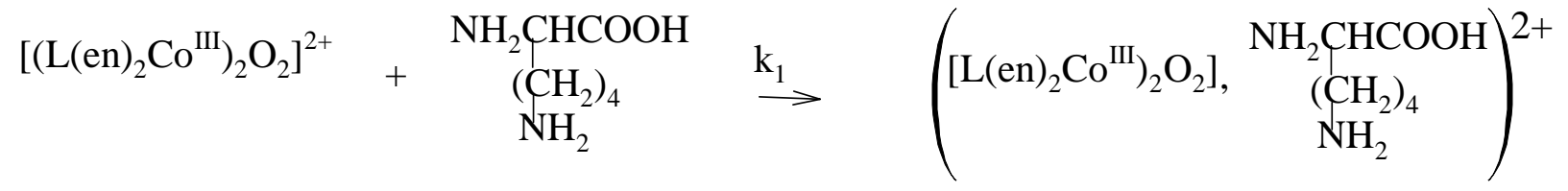

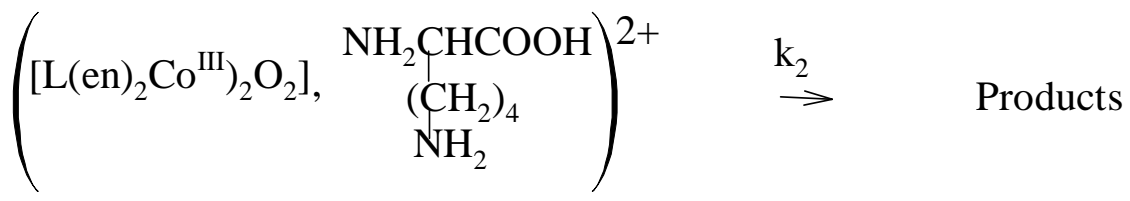

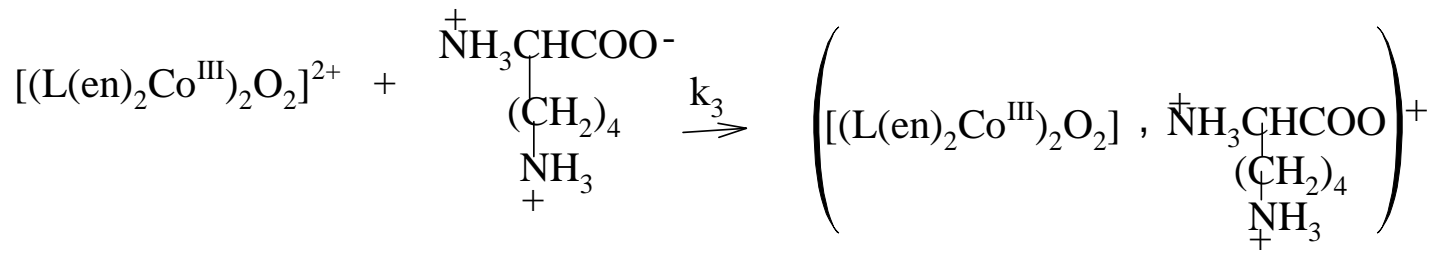

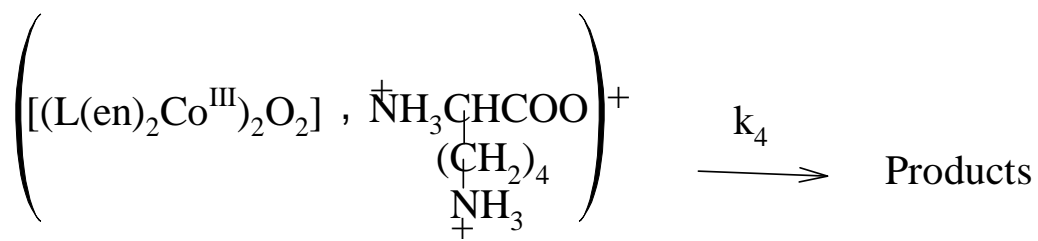

With reactions (6) and (8) as slow steps and applying steady state condition

$$
\text { Rate }=\left(\frac{k_{1}}{k_{2}}+\frac{K_{1} k_{3}}{k_{4}}\left[H^{+}\right]^{-1}\right)[\text { Complex }][\text { Lys }]
$$


Table 2: Dependence of rate constant by cations and anions for the redox reaction of the $\left[\mathrm{LCo}\left(\mu-\mathrm{O}_{2}\right) \mathrm{CoL}\right]^{2+}$. [1ygine] system at $\mathrm{I}=0.5 \mathrm{~mol} \mathrm{dm}^{-3}$ $(\mathrm{NaCl}) \mathrm{T}=24 \pm 1^{\circ} \mathrm{C}$, [lysine $]=1.2^{-2} 10^{-2} \mathrm{~mol} \mathrm{dm}^{-3},\left[\mathrm{LCo}\left(\mu-\mathrm{O}_{2}\right) \mathrm{CoL}\right]^{2+}$ $=1.410^{-4} \mathrm{~mol} \mathrm{dm}^{-3}, \lambda_{\max }=420 \mathrm{~nm},\left[\mathrm{H}^{+}\right]=1.8 \times 10^{-2} \mathrm{~mol} \mathrm{dm}^{-2}$

\begin{tabular}{|c|c|c|}
\hline $10^{3}\left[\mathrm{Ca}^{2+}\right]\left(\mathrm{mol} \mathrm{dm}^{-3}\right)$ & $10^{2} \mathrm{k}_{1}\left(\mathrm{~s}^{-1}\right)$ & $\mathrm{k}_{2}\left(\mathrm{dm}^{3} \mathrm{~mol}^{-1} \mathrm{~s}^{-1}\right)$ \\
\hline 00.0 & 3.69 & 3.08 \\
\hline 40.0 & 3.02 & 2.52 \\
\hline 60.0 & 2.98 & 2.41 \\
\hline 80.0 & 2.77 & 2.31 \\
\hline 100.0 & 2.60 & 2.17 \\
\hline 120.0 & 2.52 & 2.10 \\
\hline 140.0 & 2.47 & 2.06 \\
\hline \multicolumn{3}{|l|}{$10^{3}\left[\mathrm{Mg}^{2^{+}}\right]\left(\mathrm{mol} \mathrm{dm}^{-3}\right)$} \\
\hline 00.0 & 3.69 & 3.08 \\
\hline 40.0 & 2.77 & 2.31 \\
\hline 60.0 & 2.46 & 2.05 \\
\hline 80.0 & 2.28 & 1.90 \\
\hline 100.0 & 1.63 & 1.36 \\
\hline 120.0 & 1.36 & 1.14 \\
\hline 140.0 & 1.10 & 0.92 \\
\hline \multicolumn{3}{|l|}{$10^{3}\left[\mathrm{CH}_{3} \mathrm{COO}\right]\left(\mathrm{mol} \mathrm{dm}^{-3}\right)$} \\
\hline 00.0 & 3.69 & 3.08 \\
\hline 40.0 & 5.14 & 4.29 \\
\hline 60.0 & 8.04 & 6.70 \\
\hline 80.0 & 8.84 & 7.37 \\
\hline 100.0 & 10.53 & 8.78 \\
\hline 120.0 & 12.71 & 10.59 \\
\hline 140.0 & 15.59 & 12.99 \\
\hline \multicolumn{3}{|l|}{$10^{3}[\mathrm{HCOO}]\left(\mathrm{mol} \mathrm{dm}^{-3}\right)$} \\
\hline 00.0 & 3.69 & 3.08 \\
\hline 40.0 & 6.62 & 5.52 \\
\hline 60.0 & 7.96 & 6.64 \\
\hline 80.0 & 8.43 & 7.03 \\
\hline 100.0 & 8.89 & 7.41 \\
\hline 120.0 & 10.72 & 8.94 \\
\hline 140.0 & 11.74 & 9.79 \\
\hline
\end{tabular}

Table 3: Dependence of the change in dielectric constant of the [LCo( $\mu$ $\left.\mathrm{O}_{2}\right) \mathrm{CoL}^{-2+}$. [lysine] system at $\mathrm{I}=0.5 \mathrm{~mol} \mathrm{dm}^{-3},(\mathrm{NaCl}), \mathrm{T}=24 \pm 1^{\circ} \mathrm{C}$, $[$ ysine $]=1.2 \times 10^{-2} \mathrm{~mol} \mathrm{dm}^{-3},\left[\mathrm{LCo}\left(\mu-\mathrm{O}_{2}\right) \mathrm{CoL}\right]^{2+}=1.4 \times 10^{-4} \mathrm{~mol} \mathrm{dm}^{-3}$, $\lambda_{\max }=420 \mathrm{~nm},\left[\mathrm{H}^{+}\right]=1.8 \times 10^{-2} \mathrm{~mol} \mathrm{dm}^{-3}$

\begin{tabular}{ccc}
\hline & & \\
\hline $\mathrm{D}$ & $10^{3} \mathrm{k}_{1}\left(\mathrm{~s}^{-1}\right)$ & $\mathrm{k}_{2}\left(\mathrm{dm}^{3} \mathrm{~mol}^{-1} \mathrm{~s}^{-1}\right)$ \\
\hline 81.00 & 36.96 & 3.08 \\
78.00 & 50.40 & 4.20 \\
75.00 & 52.80 & 4.40 \\
72.00 & 56.16 & 4.68 \\
70.00 & 58.92 & 4.91 \\
67.00 & 63.72 & 5.31 \\
64.00 & 66.60 & 5.55 \\
\hline
\end{tabular}

Equation (8) is in conformity with the observed rate law.

\subsection{CONCLUSION}

The kinetics and mechanisms of oxidation of Lysine by $\mu$ peroxo-bis[bis(ethylenediamine)succinimidato

dicobalt(III)]dinitratedihydrate was carried out under the stated experimental condition. The reaction showed stoichiometry of $1: 1$, was found to be first order with respect to the concentration of each reactant species and second order overall. The reaction also displayed inverse acid dependence and showed that the activated complex composed of like charged species. Free radicals were unimportant in this reaction and result of appropriate tests did not indicate formation of binuclear intermediate complex formation. The outer sphere mechanism is proposed for the reaction.

\subsection{Conflict Of Interest}

All Authors have declared that there are no conflicts of interest.

\section{Authors Contribution}

Idris S.O. and Onu A.D. designed the experiment and Adetoro A carried out the work and wrote the manuscript. The manuscript was thoroughly read and corrected by Idris S.O., Onu A.D., and Okibe F.G.

\section{REFERENCES}

Devra, V., 2005, Kinetics and mechanism of silver (I) catalyzed oxidation of alanine by cerium (IV) in perchloric acid medium. Journal of the Indian Chemical Society 82, 290-294.

Elias, H., 1992, RG Wilkins: Kinetics and Mechanism of Reactions of Transition Metal Complexes, 2nd Thoroughly Revised Edition. VCH, Weinheim 1991. ISBN 3-527-28389-7..

Goel, A., Sharma, R., 2012, A kinetic and mechanistic study on the oxidation of arginine and lysine by hexacyanoferrate (III) catalysed by iridium (III) in aqueous alkaline medium. Journal of Chemical Engineering and Materials Science 3, 1-6.

Goel, A., Sharma, S., 2010, Mechanistic study of the oxidation of 1phenylalanine by hexacyanoferrate (III) catalyzed by iridium (III) in aqueous alkaline medium. Transition Metal Chemistry 35, 549-554.

Goel, A., Verma, G., Singh, H., 2002, Kinetics and mechanism of iridium (III) chloride catalyzed oxidation of ethylene glycol and methyl glycol by hexacyanoferrate (III) in aqueous alkalinemedium. Journal of the Indian Chemical Society 79, 665-667.

Gowda, N.M.M., Rangappa, K.S., Mahadevappa, D.S., 1986, Oxidimetric determination of amino acids and their metal complexes with organic monochloramines. Analyst 111, 1423-1429.

Gupta, K., Gupta, Y., 1984, Hydrogen-Ion dependence of Reaction Rates and mechanism. J. Chem. Educ 61, 972.

Harihar, A., Kembhavi, M., Nandibewoor, S., 2000, Kinetics of oxidative degradation of $\mathrm{L}(+)$ lysine by alkaline permanganate-A mechanistic approach.

Hosamani, R., Nandibewoor, S., 2009, Mechanistic study of ruthenium (III) catalysed oxidation of L-lysine by diperiodatoargentate (III) in aqueous alkaline medium. Journal of chemical sciences 121, 275281. 
Iyun, J., Ayoko, G., Lawal, H., 1992, The Stoichiometry And Kinetics Of Oxidation Of 1, 4-Benzenediol By Diaquotetrakis (2, 2'-Bipyridine)$\mathrm{Mu}-\mathrm{Oxodiruthenium} \mathrm{(Iii)} \mathrm{Cation} \mathrm{in} \mathrm{Perchlorate} \mathrm{Medium.} \mathrm{Indian}$ Journal Of Chemistry Section A-Inorganic Bio-Inorganic Physical Theoretical \& Analytical Chemistry 31, 943-946.

Iyun, J., Ukoha, P., 1999, Kinetics and mechanism of oxidation of 1, 3dihydroxybenzene by trioxoiodate $(\mathrm{V})$ ion in aqueous perchloric acid medium.

Gouda N.M.M., Mahadevappab D.S., Rangappa K.S; Thimmegouda B., 1986, Oxidimetric determination of amino acids and their metal complexes with organic monochloramies International Journal of Chemical Kinetic, 2, 165-178.

Mohanty, B., Behera, J., Acharya, S., Mohanty, P., Pantaik, A., 2013, Metal ion catalyzed oxidation of L-lysine by alkaline permanganate Ion-A kinetic and mechanistic approach. Chem Sci Trans 2, 51-60.

Orhan B., 2009, Synthesis and structural characterization of a novel peroxo bridged binuclear cobalt(III) complex of succinimide showing three varieties of hydrogen bonding interaction.

Journal of Chemical Science. 121(3), 267-273.

Roberts, J.D., Caserio, M.C., 1977, Basic principles of organic chemistry. WA Benjamin, Inc.

Wilkins, R.G., 2002, Kinetics and mechanism of reactions of transition metal complexes, $2^{\text {nd }} E d$. Wiley-VCH \& Co 